\title{
Body mass composition and dietary habits in adolescents with polycystic ovary syndrome
}

\author{
Agnieszka A. Bialka-Kosiec, Krzysztof Wilk, Magdalena Pytel, Violetta Skrzypulec-Plinta, \\ Rafal Stojko, Agnieszka Drosdzol-Cop
}

Department of Paediatric Surgery and Urology, John Paul II Upper Silesian Child Health Centre, Medical University of Silesia, Katowice, Poland

\begin{abstract}
Objectives: The aim of the present study is to assess differences in body composition between female participants in the study group who suffer from PCOS versus a healthy control group.

Material and methods: The study included 85, 14-22-year-old, female participants. Participants belonged to one of two groups. Thirty seven participants with a diagnosis of PCOS were in the clinical group, and 48 participants were in the healthy control group with no prior diagnosis of PCOS.

Results: A statistically significant difference between groups was found in their answer regarding diet. A correlation was found between the body fat index and the use of dieting among participants; participants with a lower body fat index (in kilograms) were less likely to be on a diet.

Conclusions: The young female participants with PCOS were shown to have similar body composition to age-matched healthy controls. However, the clinical group with PCOS reported more frequent use of dieting, with less use of exercise.

Key words: PCOS; body mass composition; dietary habits; young females
\end{abstract}

Ginekologia Polska 2019; 90, 10: 589-595

\section{INTRODUCTION}

Polycystic ovary syndrome (PCOS) is a heterogeneous endocrine disorder that is diagnosed in $3-6 \%$ of adolescent females. It is estimated that $16 \%$ of women who report to a gynecological clinic with a menstrual disorder receive a final diagnosis of PCOS. The etiology of the syndrome is not fully understood; however, it is known that genetics play a significance role in determining risk $[1,2]$.

The most commonly used criteria for the diagnosis of polycystic ovary syndrome are The Rotterdam Criteria proposed at the Rotterdam conference with the participation of the European Society of Human Reproduction and Embryology (ESHRE) and the American Society of Reproduction Medicine (ASRM). Determining the diagnosis based on these criteria, however, causes difficulties in the group of adolescents and women in the perimenopausal period. In adolescents, the presence of clinical and biochemical symptoms of hyperandrogenism should be particularly taken into account. Some of the symptoms that meet the criteria for polycystic ovary syndrome may be the result of physiological changes in the body of an adolescent woman. Therefore, in girls, diagnosis is based modified Rotterdam criteria, i.e. all three criteria must be met (and not 2 out of 3 as for adult women):

1. Oligo- or anovulation (adolescent's cycle lasting $>45$ days, or amenorrhea $>90$ days);

2. Biochemical exponents of hyperandrogenism or hirsutism;

3. The volume of one of the ovaries $>12 \mathrm{~mL}$ or $>24$ vesicles in the ovary in the ultrasound examination of the pelvis. Menstrual disorders should be confirmed no earlier than two years after the menarche [1-3].

In 2018, the latest recommendations were issued based on international evidence-based guidelines for the assessment and management of polycystic ovary syndrome. It was found that ultrasound should not be used in the diagnosis of PCOS in girls of gynecological age $<8$ years (i.e. $<8$ years after the first menstruation), due to the high incidence of polycystic ovaries at this stage of life [4].

Characteristic for PCOS are the coexistence of pre-diabetic conditions (abnormal fasting glucose levels and 
glucose intolerance), type 2 diabetes, hyperinsulinaemia, insulin resistance and obesity. Attention is drawn to the following sequence of events: the results of low birth weight are successively: accelerated weight gain, premature adrenarche and PCOS. An increase in body mass is most likely the key predictor of the severity of the syndrome in early puberty. The therapeutic priority for women with PCOS is therefore to maintain a normal weight, or lose weight in cases where the woman is overweight. Studies show that the loss of $10 \%$ of one's body weight at diagnosis aids in the return of regular cycles, fertility as well as other metabolic parameters; such weight loss also increases insulin sensitivity in tissues [1, 5-6].

However, the calculation of body mass from a scale does not provide any important information about the amount of adipose tissue and muscle in the body or the overall hydration and condition of the body. As such, body mass index (BMI) is not a sufficient measure to determine the efficiency of human metabolism. In turn, a body composition analysis using the bioimpedance method can generate this critical information. The bioimpedance analysis (BIA) measures the impedance (the type of resistance) of tissues through low-voltage electric current [7].

\section{Objectives}

The aim of the present study is to assess differences in body composition between female participants in the study group who suffer from PCOS versus a healthy control group. The plan is to evaluate the individual body mass elements in association with the level of Anti-Mullerian Hormone (AMH) and leptin, in an attempt to determine whether lifestyle has an effect on the body composition of females diagnosed with PCOS versus healthy controls.

\section{MATERIAL AND METHODS}

Participants

The study included 85, 14-22-year-old, recruits. Participants belonged to one of two groups. Thirty seven participants with a diagnosis of PCOS were in the clinical group, and 48 participants were in the healthy control group with no prior diagnosis of PCOS. The female participants were patients recruited from the Department of Pediatric Endocrinology of the Upper Silesian Children's Health Center John Paul II in Katowice.

Inclusion criteria for all participants in the study included the following: being 14-22 years old and having experienced menarche for at least two years prior to the study. Exclusion criteria included the use of any pharmacotherapy (e.g., hormonal therapy, contraceptives, NSAIDs) and the presence of any systemic disease (e.g., cardiovascular disease, diabetes, endocrine disease, autoimmune disorders). Participants included in the clinical group were rated according to the Rotterdam Criteria ( $3 / 3$ criteria) to determine the presence of PCOS. Only women who formally consented to participate in the study, or girls whose guardians consented to their participation, were included in the study.

All participants in the study were informed, in detail, about the purpose and methodology. Consent was obtained from all participants. Ethics approval for the study was obtained from the Bioethical Commission of the Medical University of Silesia in Katowice. Throughout the implementation of the research, researchers strictly abided by the ethical principles outlined in the Declaration of Helsinki.

\section{Methods}

Participants were required to answer background questions about their demographics, gynecological history, general medical history including relevant diseases, and lifestyle using the HBSC Questionnaire - a mandatory, standardized questionnaire in Poland in 2013/2014. HBSC is an international study on the health behavior of school children, which are carried out periodically. The questionnaire consists of mandatory questions used by all countries, as well as optional questions. The following indicators were used: meals, physical activity, dietary habits, self-esteem. Based on participant medical history, the length of the menstrual cycle was determined. A regular menstrual cycle (eumenorrhea) was defined as one that cycled every $21-45$ days with a length of menstrual bleeding of 3-7 days, and an estimated blood loss of 5-80 mL.

Subsequently, anthropometric measurements (i.e., height, weight, and BMI) were taken for each participant. The measurements were performed in the morning after overnight fasting. The weight (without shoes, in light clothing) was measured using the RADWAG certified electronic scale. The height (in an upright standing position, without shoes) was measured using a stadiometer. The weight was obtained with an accuracy of $0.1 \mathrm{~kg}$, while the height was obtained with an accuracy of $0.5 \mathrm{~cm}$.

The body composition analysis was performed with the use of the BodystatQuadscan 4000. The measurement was performed 10 minutes after obtaining the supine position. The electrodes in accordance to the tetra polar system were placed in the mid-dorsal line of the hands and feet.

The intensity of participants' hirsutism was assessed in accordance with the Ferriman-Gallwey score (the quantitative assessment of body hair in nine different parts of the body: upper lip, chin, upper and lower abdomen, chest, upper arms, as well as thighs, upper and lower back). The severity of hirsutism in each part of the body was rated on a scale from 0 to 4 points. Hirsutism was diagnosed with a score of 8 or more. A transvaginal ultrasound of the pelvis was performed on sexually active women and a transab- 
dominal ultrasound (with a full bladder) was performed on not sexually active women.

Subsequently, a series of laboratory procedures were completed. The blood was collected in the morning after overnight fasting, between the 2 nd and the 5 th day of the cycle in the early follicular phase of the menstrual cycle. Then the level of total and free testosterone, androstenedione, leptin, AMH in serum, insulin, glucose, and the mathematical model of insulin resistance HOMA-IR were measured. Insulin resistance was diagnosed at HOMA-IR $\geq 2.5$.

The diagnosis of PCOS was made based on the criteria set by the European Society for Human Reproduction (ESHRE) and the American Society of Reproductive Medicine (ASRM): 1) oligoovulation or anovulation occurred at least 2 years after the menarche), 2) biochemical exponents of hyperandrogenism and hirsutism, 3) the volume of one of the ovaries $>12 \mathrm{~mL}$ in a pelvic ultrasound scan. PCOS in the clinical group of participants was recognized if all of the three criteria were met.

\section{RESULTS}

The healthy control and clinical groups were compared on the variables investigated in this study. The mean age of female participants in the clinical group was $19.4 \pm 2.4$ years, while the mean age of participants in the control group was $20.0 \pm 2.2$ years. The groups were matched on age, with no significant difference between them $(p=0.32)$. Also there were no significant differences between groups on measures of weight, height and BMI (Tab. 1).

A statistically significant difference between groups was found in their answer regarding diet $(p=0.02)$. When asked, "Are you following any diet or doing anything to lose your weight?", $54.7 \%$ of participants in the control group answered that they did not need to adhere to any specific diet because their weight is where it is supposed to be, whereas only $21.21 \%$ of participants in the clinical group answered in this way. In the clinical group, $27.27 \%$ of participants reported that they currently use or have used in the past some dietary plan, while only $14.29 \%$ of participants in the control group provided this answer. However, no statistical significance was found between the quality of the meals that each group consumed. The girls from both groups consumed fruits and vegetables as well as sweets and sweet drinks with equal frequency. The results of this analysis are presented in Table 2. The participants in the clinical group reported significantly less engagement in sports, defined as participation in physical activity lasting at least 60 minutes per week $(p=0.02)$. There was no statistical significance between the self-assessment measure of participants in the control versus clinical group in terms of physical appearance (Fig. 1). Furthermore, when asked about the number of hours spent watching movies, playing games, using computers and social networks during their free time, there were no significant differences between groups in their answers.

Table 3 presents the distribution of individual body mass components in the clinical versus control groups. An association was noted between the leptin level and body composition. A statistically significant correlation was found between the mass of adipose tissue (described in kilograms and percentage) and the content of water in the body (Tab. 4).

\begin{tabular}{|c|c|c|c|}
\hline $\begin{array}{l}\text { Statistical } \\
\text { parameter }\end{array}$ & $\begin{array}{l}\text { Study group } \\
\text { [average } \pm \text { SD] }\end{array}$ & $\begin{array}{l}\text { Control group } \\
\text { [average } \pm \text { SD] }\end{array}$ & $\begin{array}{l}\text { Mann-Whitney } \\
\text { U test }\end{array}$ \\
\hline Height $[\mathrm{cm}]$ & $165.9 \pm 6.5$ & $165.5 \pm 6.1$ & $p=0.49$ \\
\hline Weight [kg] & $64.3 \pm 12.4$ & $61.8 \pm 9.9$ & $p=0.31$ \\
\hline BMI $\left[\mathrm{kg} / \mathrm{m}^{2}\right]$ & $23.3 \pm 4.1$ & $22.6 \pm 3.5$ & $p=0.55$ \\
\hline
\end{tabular}

$\mathrm{BMI}$ - body mass index

Table 2. The frequency of consumption of particular products by females from the test and control groups

\begin{tabular}{|c|c|c|c|c|c|c|c|c|}
\hline \multirow{3}{*}{$\begin{array}{l}\text { Frequency of } \\
\text { consumption }\end{array}$} & \multicolumn{8}{|c|}{ Products } \\
\hline & \multicolumn{2}{|l|}{ Fruits } & \multicolumn{2}{|c|}{ Vegetables } & \multicolumn{2}{|c|}{$\begin{array}{l}\text { Sweets (candy, } \\
\text { chocolate) }\end{array}$} & \multicolumn{2}{|c|}{$\begin{array}{l}\text { Coca-cola or other sweet } \\
\text { drinks }\end{array}$} \\
\hline & $\begin{array}{l}\text { Study } \\
\text { group }\end{array}$ & $\begin{array}{l}\text { Control } \\
\text { group }\end{array}$ & $\begin{array}{l}\text { Study } \\
\text { group }\end{array}$ & $\begin{array}{l}\text { Control } \\
\text { group }\end{array}$ & $\begin{array}{l}\text { Study } \\
\text { group }\end{array}$ & $\begin{array}{l}\text { Control } \\
\text { group }\end{array}$ & $\begin{array}{l}\text { Study } \\
\text { group }\end{array}$ & $\begin{array}{l}\text { Control } \\
\text { group }\end{array}$ \\
\hline Never & $0 \%$ & $0 \%$ & $2.94 \%$ & $0 \%$ & $2.94 \%$ & $2.27 \%$ & $29.41 \%$ & $22.73 \%$ \\
\hline Less than once a week & $6.06 \%$ & $2.27 \%$ & $0 \%$ & $9.09 \%$ & $11.76 \%$ & $13.64 \%$ & $17.65 \%$ & $47.73 \%$ \\
\hline Once a week & $21.21 \%$ & $15.91 \%$ & $0 \%$ & $9.09 \%$ & $17.65 \%$ & $13.64 \%$ & $20.59 \%$ & $15.91 \%$ \\
\hline 2-4 days a week & $18.18 \%$ & $36.36 \%$ & $41.18 \%$ & $20.45 \%$ & $32.35 \%$ & $34.09 \%$ & $14.71 \%$ & $11.36 \%$ \\
\hline 5-6 days a week & $18.18 \%$ & $15.91 \%$ & $20.59 \%$ & $20.45 \%$ & $8.82 \%$ & $11.36 \%$ & $8.82 \%$ & $0 \%$ \\
\hline One time every day & $18.18 \%$ & $11.36 \%$ & $8.82 \%$ & $22.73 \%$ & $11.76 \%$ & $15.91 \%$ & $2.94 \%$ & $2.27 \%$ \\
\hline More than once every day & $18.18 \%$ & $18.18 \%$ & $26.47 \%$ & $18.18 \%$ & $14.71 \%$ & $9.09 \%$ & $5.88 \%$ & $0 \%$ \\
\hline Yates's chi-squared test & \multicolumn{2}{|l|}{$p=0.60$} & \multicolumn{2}{|l|}{$p=0.10$} & \multicolumn{2}{|l|}{$p=0.98$} & \multicolumn{2}{|l|}{$p=0.10$} \\
\hline
\end{tabular}




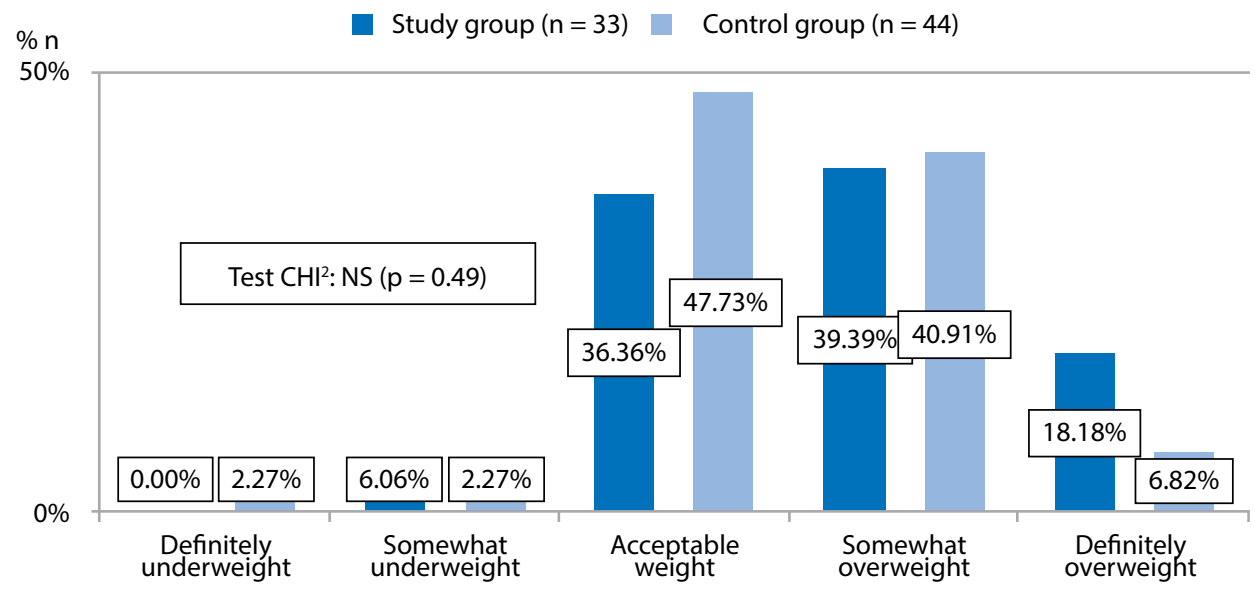

Self-assessment of appearance of respondents

Figure 1. Self-assessment of appearance among study and control groups of females

Table 3. Distribution of body mass components amongst the study and control groups

\begin{tabular}{|l|l|l|l|l|l|l|l|}
\hline $\begin{array}{l}\text { Body mass } \\
\text { components }\end{array}$ & \multicolumn{2}{|l|}{ Study group } & \multicolumn{2}{l|}{ Control group } & $\begin{array}{l}\text { Chi-squared } \\
\text { test }\end{array}$ \\
\hline Below the norm & Norm & Above the norm & Below the norm & Norm & Above the norm \\
\hline Body fat $[\mathrm{kg}]$ & $1(3.45 \%)$ & $6(20.69 \%)$ & $22(75.86 \%)$ & $2(4.26 \%)$ & $18(38.30 \%)$ & $27(57.45 \%)$ & $\mathrm{p}=0.28$ \\
\hline FFM $[\mathrm{kg}]$ & $1(3.45 \%)$ & $5(17.24 \%)$ & $23(79.31 \%)$ & $7(14.89 \%)$ & $13(27.66 \%)$ & $27(57.45 \%)$ & $\mathrm{p}=0.15$ \\
\hline Water content $[\%]$ & $22(75.86 \%)$ & $7(24.14 \%)$ & $0(0.00 \%)$ & $25(53.19 \%)$ & $21(44.68 \%)$ & $1(2.13 \%)$ & $p=0.17$ \\
\hline Water content $[\mathrm{kg}]$ & $22(75.86 \%)$ & $7(24.14 \%)$ & $0(0.00 \%)$ & $26(55.32 \%)$ & $20(42.55 \%)$ & $1(2.13 \%)$ & $\mathrm{p}=0.23$ \\
\hline
\end{tabular}

FFM - fat-free mass

\begin{tabular}{|c|c|c|c|c|c|}
\hline \multirow{2}{*}{$\begin{array}{l}\text { Body mass } \\
\text { component }\end{array}$} & \multirow[b]{2}{*}{ Category } & \multicolumn{2}{|l|}{ Study group } & \multicolumn{2}{|l|}{ Control group } \\
\hline & & $\begin{array}{l}\text { Average } \pm \text { standard } \\
\text { deviation. }\end{array}$ & U Mann-Whitney test & $\begin{array}{l}\text { Average } \pm \text { standard } \\
\text { deviation }\end{array}$ & U Mann-Whitney test \\
\hline \multirow{3}{*}{ Body fat index [\%] } & Below the norm & 8.11 & \multirow{3}{*}{$p=0.008$} & $4.98 \pm 2.96$ & \multirow{3}{*}{$p=0.004$} \\
\hline & Norm & $6.20 \pm 2.84$ & & $9.11 \pm 6.30$ & \\
\hline & Above the norm & $16.40 \pm 11.18$ & & $16.90 \pm 16.04$ & \\
\hline \multirow{3}{*}{ Body fat [kg] } & Below the norm & 8.11 & \multirow{3}{*}{$p=0.03$} & $5.54 \pm 2.23$ & \multirow{3}{*}{$p=0.001^{*}$} \\
\hline & Norm & $6.39 \pm 3.13$ & & $10.65 \pm 6.69$ & \\
\hline & Above the norm & $15.92 \pm 11.17$ & & $16.78 \pm 16.14$ & \\
\hline \multirow{3}{*}{ FFM [kg] } & Below the norm & $19.14 \pm 17.40$ & \multirow{3}{*}{$p=0.61$} & $10.00 \pm 6.73$ & \multirow{3}{*}{$p=0.07$} \\
\hline & Norm & $12.67 \pm 8.19$ & & $15.93 \pm 16.30$ & \\
\hline & Above the norm & - & & - & \\
\hline \multirow{3}{*}{ Water content [\%] } & Below the norm & $16.40 \pm 11.18$ & \multirow{3}{*}{$p=0.006$} & $17.46 \pm 16.53$ & \multirow{3}{*}{$p=0.003$} \\
\hline & Norm & $6.47 \pm 2.69$ & & $8.89 \pm 6.06$ & \\
\hline & Above the norm & - & & 7.07 & \\
\hline Water content [kg] & Below the norm & $16.40 \pm 11.18$ & $p=0.006$ & $17.10 \pm 16.30$ & $p=0.003$ \\
\hline
\end{tabular}

*Kruskal-Wallis $\mathrm{H}$ test was applied to 3 categories; FFM — fat-free mass

However, there was no correlation between the level of AMH and individual body mass components. See Table 5 for findings.
A correlation was found between the body fat index and the use of dieting among participants; participants with a lower body fat index (in kilograms) were less likely to be on 
Table 5. Spearman's correlation of the body mass componentswith the value of AMH among the study and control groups

\begin{tabular}{|c|c|c|}
\hline \multirow{2}{*}{ Correlations } & \multicolumn{2}{|l|}{ AMH } \\
\hline & Study group & Control group \\
\hline Body fat index [\%] & $\begin{array}{l}R=-0.16 \\
p=0.40\end{array}$ & $\begin{array}{l}R=-0.08 \\
p=0.61\end{array}$ \\
\hline Body fat [kg] & $\begin{array}{l}R=-0.24 \\
p=0.21\end{array}$ & $\begin{array}{l}R=0.03 \\
p=0.87\end{array}$ \\
\hline FFM [kg] & $\begin{array}{l}R=0.08 \\
p=0.68\end{array}$ & $\begin{array}{l}R=0.08 \\
p=0.61\end{array}$ \\
\hline Water content [\%] & $\begin{array}{l}R=0.10 \\
p=0.60\end{array}$ & $\begin{array}{l}R=-0.01 \\
p=0.95\end{array}$ \\
\hline Water content [kg] & $\begin{array}{l}R=-0.10 \\
p=0.59\end{array}$ & $\begin{array}{l}R=0.0 \\
p=0.91\end{array}$ \\
\hline
\end{tabular}

FFM — fat-free mass a diet (Fig. 2). The same association was found between the measure of Fat-free mass (FFM) and the likelihood of being on a diet (Fig. 3). Finally, participants with a higher body fat index were more likely to see themselves as 'somewhat, or definitely too fat' (Fig. 4).

\section{DISCUSSION}

The incidence of PCOS increases rapidly between 12 and 14 years of age, peaking between 15 and 24 years of age and gradually decreasing until the individual reaches menopause. For this reason, research in this area with young females is so important. It appears that research on the etiopathogenesis of PCOS, which remains unclear, should focus on this age group [8].
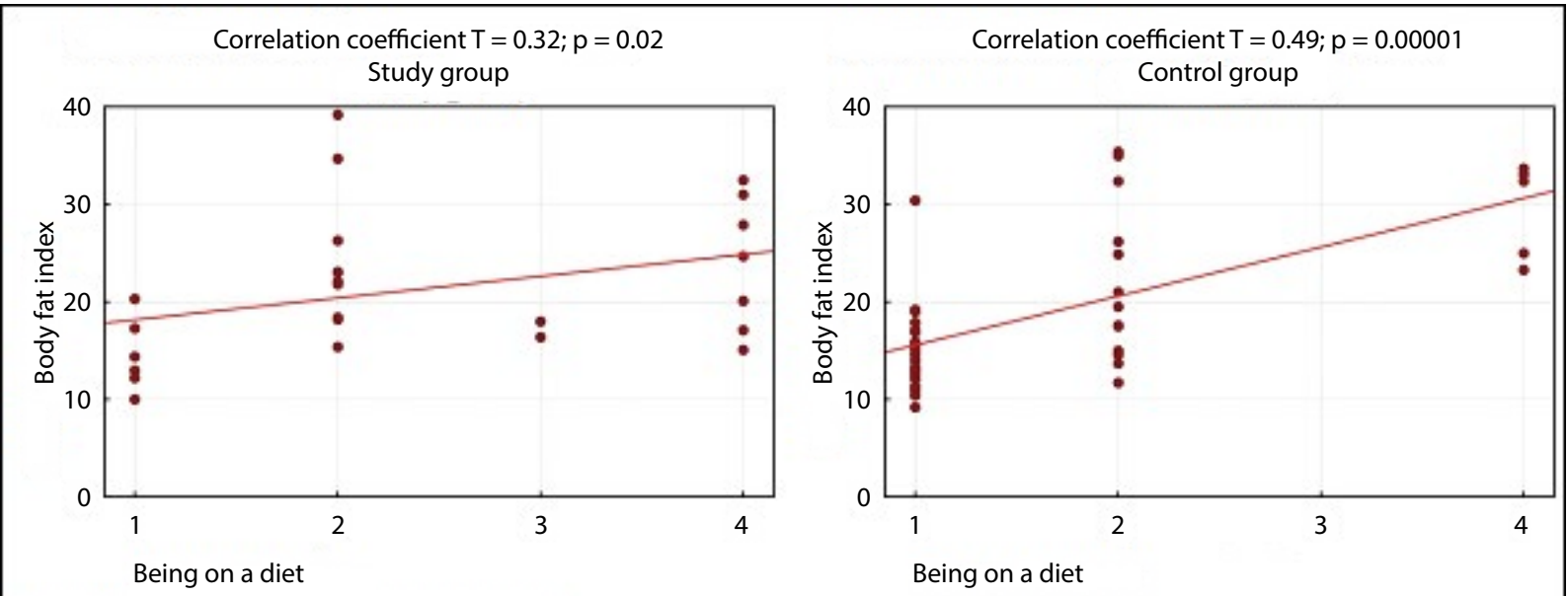

\section{Currently on a diet to lose weight}

$1-$ no, my weight is where it is supposed to be; $2-$ no, but I should lose some weight;

3 - no, because I should gain some weight; 4 - yes

Figure 2. Correlation between body fat index $(\mathrm{kg})$ and current diet among study and control groups

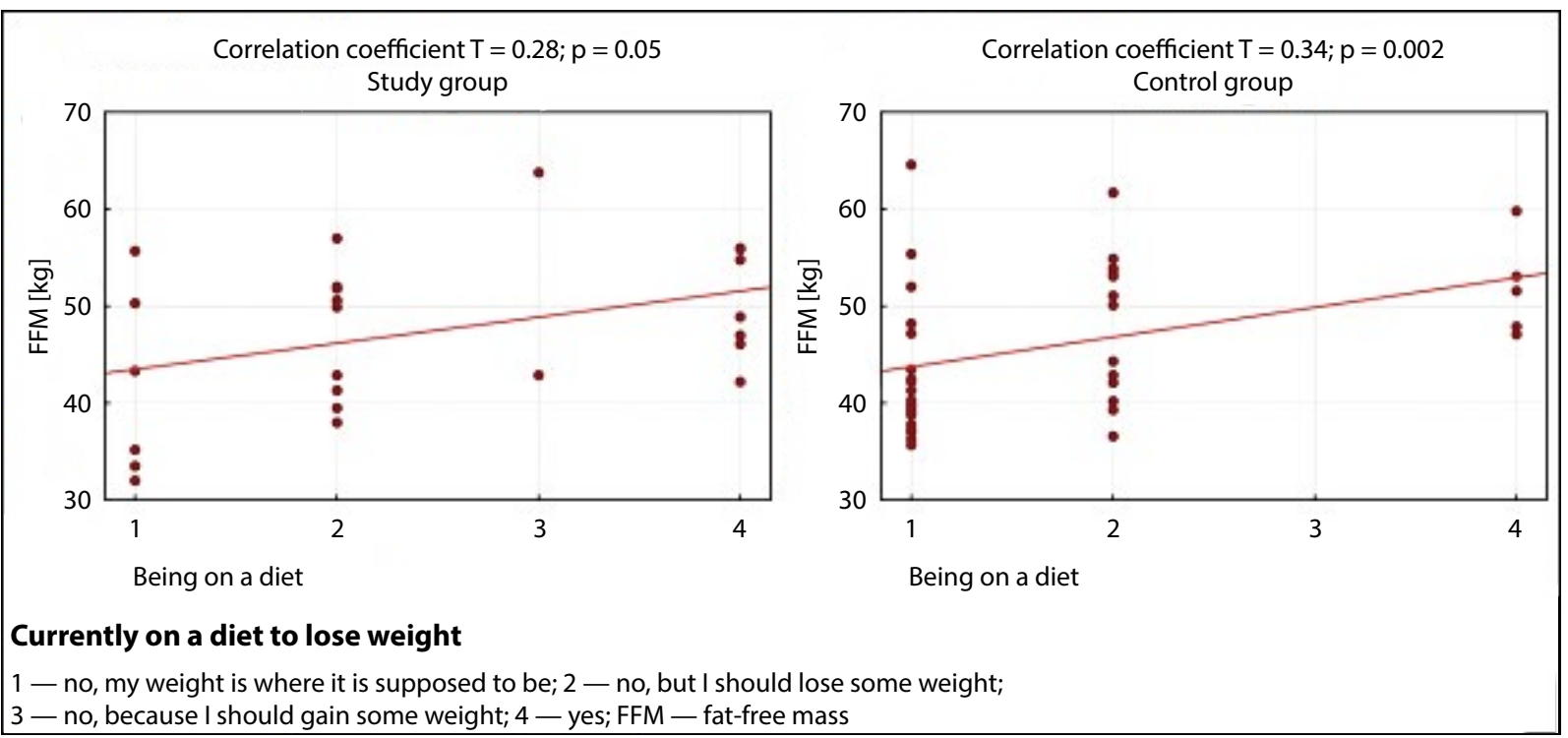

Figure 3. Correlation betweenFat-free mass $(\mathrm{kg})$ and current diet among study and control groups 


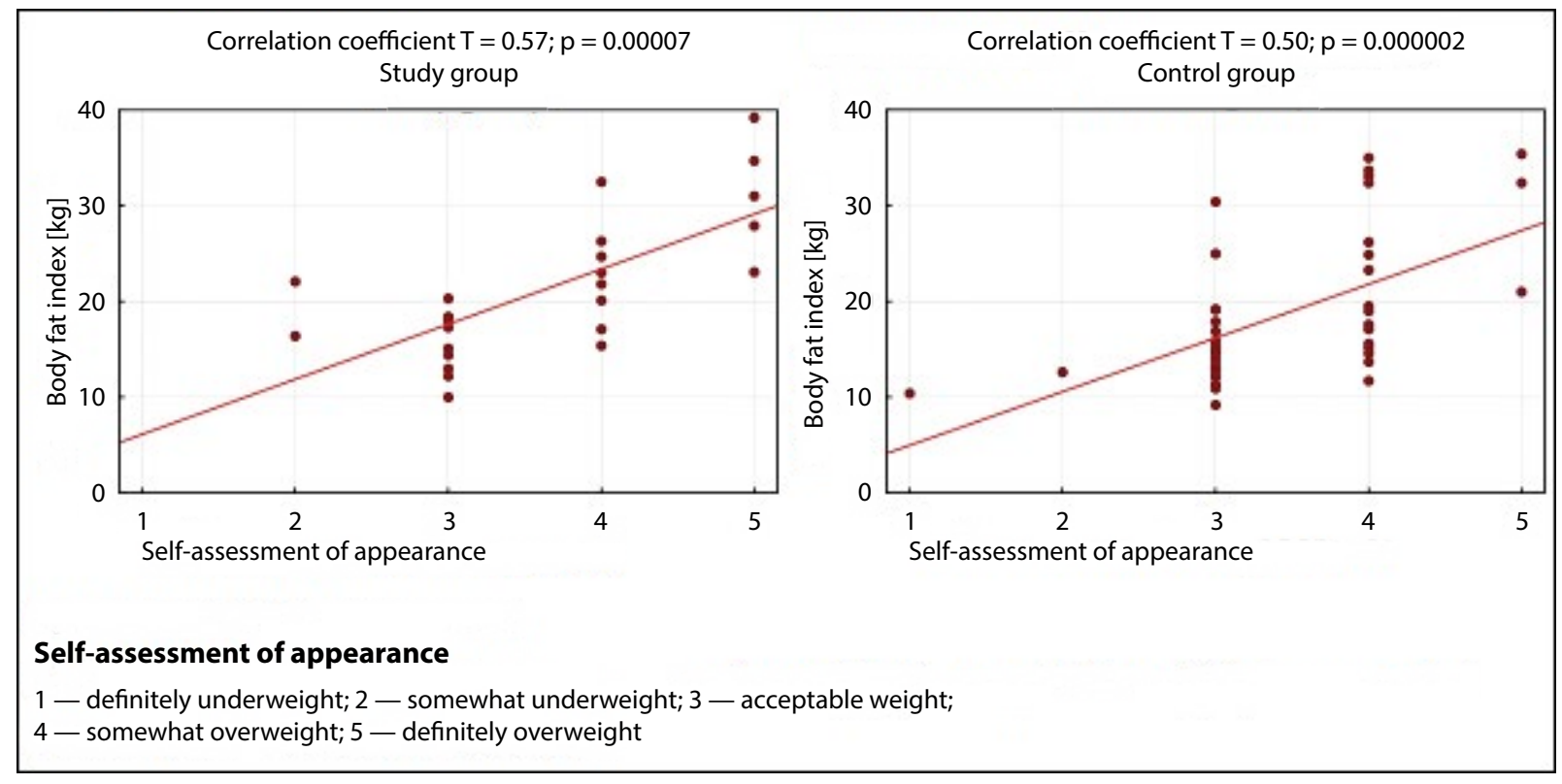

Figure 4. Correlation between body fat index $(\mathrm{kg})$ and self-assessment of appearance among study and control groups

The common features of PCOS, including as hyperinsulinaemia, metabolic dysfunction and hyperandrogenemia, are associated with the accumulation of excess adipose tissue. Regardless of BMI, adipose tissue distribution along with proportionately greater abdominal obesity may further exacerbate metabolic abnormalities associated with PCOS [9].

Our study did not show statistically significant differences between the body mass composition of female participants in a healthy control versus clinical group (participants diagnosed with PCOS). The absence of a statistically significant difference in the body mass composition between healthy and clinical groups of women, measured using the bioimpedance method, was previously reported by Geronikolou et al. [10]. Furthermore, Attlee et al. [11] used BIA analysis to discover that FFM and percentage of adipose tissue did not significantly differ between young females with and without PCOS. This finding expands on other studies that did not find a difference between anthropometric measurements including weight, BMl, waist and hip circumference, in women with PCOS versus women without PCOS [12]. In turn, Ezeh et al. [13] studied a group of adult female patients with PCOS and found an unfavorable body composition, characterized by an increased fat-to-muscle ratio. In the studies comparing only BMI between groups, women with PCOS had a significantly higher BMI compared to the control group (without PCOS) [14].

According to the research, $30-70 \%$ of the population around the world with PCOS is overweight or obese [15]. The increasing number of metabolic and reproductive dysfunctionsassociated with adipose tissue disorders, such as altered cytokine secretion, chronic low grade inflammation and oxidative stress, is related to an increased occurrence of PCOS [15].
Adipose tissue is not only the body's energy storage but also the largest endocrine and paracrine organ that synthesizes the biologically active substances. These substances are called adipokines and they act both at autocrine/paracrine and at endocrine levels. One of these adipokines is called leptin. The concentration of the leptin in plasma is directly proportional to the amount of adipose tissue. In obese individuals, prolonged existence of high concentrations of leptin leads to leptin resistance and, as a consequence, to increased resistance of peripheral tissues to insulin. According to some studies, concentrations of leptin in young females with PCOS are directly proportional to BMI, body fat index, waist circumference and HOMA-IR index, and are higher than those in healthy young females. Our study confirmed that the relation between leptin and body fat index exists in both the clinical and control groups. It is commonly believed that the concentration of leptin in the plasma of young females is a determining factor in the onset of puberty. The delay in puberty onset in females with low body fat index and the occurrence of secondary amenorrhea are most likely associated with a decrease in leptin levels [16-19].

It has been found that lifestyle changes can improve body mass composition, symptoms of hyperandrogenism and insulin resistance in women with PCOS, although there is no evidence of a positive effect of these changes on the glycemic profile and lipid profile in participants. Nevertheless, lifestyle changes are recommended as a first-line treatment in overweight ad obese adolescents with suspected PCOS. In our study, young females from the clinical group reported significantly more adherence to a diet and less participation in sports. Meanwhile, it was that yoga classes 
were more effective than conventional physical exercises in improving glucose, lipids and insulin values. No difference was noted between groups in the time that participants reported to use the computer or television. Participants with a higher body fat index were more likely to be on a diet, or only declared it, across groups [8].

Psychological interventions are also an important consideration in this group of patients. An Endocrine Society Clinical Practice Guideline indicate an increased incidence of depression and anxiety in women with PCOS. It is suggested that women with PCOS be screened for depression and anxiety. Obesity was indicated as the main factor causing depression and emotional stress among young females with PCOS. It is stated that the main psychological and behavioral interventions that improve mental health in young female with PCOS are: good sleep, lifestyle changes (healthy diet and prevention of sedentary lifestyles) and regular exercise. These strategies are designed to reduce stress and depression through, among others, weight loss $[8,20]$.

One of the limitations of the present study is a small sample size in the clinical group. However, due to the occurrence of PCOS and the range of age of participants in the study, collecting a larger sample size would require a much longer time frame. Finally, body mass composition was measured using $\mathrm{BIA}$, which is less sensitive and accurate than other methods such as DXA or MRI. However, BIA has been shown to be significantly more cost-effective and provides comparable results. Unfortunately, in the literature there are no such studies conducted on a group of young PCOS girls regarding body composition and dietary habits.

\section{CONCLUSIONS}

The young female participants with PCOS were shown to have similar body composition to age-matched healthy controls. However, the clinical group with PCOS reported more frequent use of dieting, with less use of exercise. There is a need for further studies in this area of research with a larger sample size in order to confirm these results. Although PCOS is considered primarily to be a gynecological condition, it is related to many systems in the human body. This can result in an increased risk of infertility, insulin resistance, metabolic syndromes, type 2 diabetes, and other health concerns. Therefore, a greater understanding of the etiopathogenesis of PCOS is of utmost importance.

\section{REFERENCES}

1. Skrzypulec-Plinta V, Drosdzol-Cop A. Pierwotny i wtórny brak miesiączki. In: Drosdzol-Cop A. ed. Ginekologia dziecięca i dziewczęca. PZWL, Warszawa 2017: 107-109.
2. Chung PW, Chan SSC, Yiu KW, et al. Menstrual disorders in a Paediatric and Adolescent Gynaecology Clinic: patient presentations and longitudinal outcomes. Hong Kong Med J. 2011; 17(5): 391-397, indexed in Pubmed: 21979477.

3. Rackow BW. Polycystic ovary syndrome in adolescents. Curr Opin Obstet Gynecol. 2012; 24(5): 281-287, doi: 10.1097/GCO.0b013e32835669ff, indexed in Pubmed: 22781076.

4. Teede HJ, Misso ML, Costello MF, et al. Recommendations from the international evidence-based guideline for the assessment and management of polycystic ovary syndrome. Fertil Steril. 2018; 110(3): 364-379.

5. Panidis D, Balaris C, Farmakiotis D, et al. Serum parathyroid hormone concentrations are increased in women with polycystic ovary syndrome. Clin Chem. 2005; 51(9): 1691-1697, doi: 10.1373/clinchem.2005.052761, indexed in Pubmed: 16037412.

6. Diamanti-Kandarakis E. PCOS in adolescents. Best Practice \& Research Clinical Obstetrics \& Gynaecology. 2010; 24(2): 173-183, doi: 10.1016/j. bpobgyn.2009.09.005.

7. Lewitt A, Mądro E, Krupienicz A. Podstawy teoretyczne i zastosowania analizy impedancji bioelektrycznej (BIA). Endokrynologia, Otyłość, Zaburzenia Przemiany Materii. 2007; 3(4): 79-84.

8. Wang FF, Pan JX, Wu Y, et al. American, European, and Chinese practice guidelines or consensuses of polycystic ovary syndrome: a comparative analysis. J Zhejiang Univ Sci B. 2018; 19(5): 354-363, doi: 10.1631/jzus. B1700074, indexed in Pubmed: 29732746.

9. Goss AM, Chandler-Laney PC, Ovalle F, et al. Effects of a eucaloric reduced-carbohydrate diet on body composition and fat distribution in women with PCOS. Metabolism. 2014; 63(10): 1257-1264, doi: 10.1016/j. metabol.2014.07.007, indexed in Pubmed: 25125349.

10. Geronikolou SA, Bacopoulou F, Cokkinos D. Bioimpedance Measurements in Adolescents with Polycystic Ovary Syndrome: A Pilot Study. Adv Exp Med Biol. 2017; 987: 291-299, doi: 10.1007/978-3-319-573793_26, indexed in Pubmed: 28971467.

11. Attlee A, Nusralla A, Eqbal R, et al. Polycystic ovary syndrome in university students: occurrence and associated factors. Int J Fertil Steril. 2014; 8(3): 261-266, indexed in Pubmed: 25379154.

12. Aydin K, Cinar N, Aksoy DY, et al. Body composition in lean women with polycystic ovary syndrome: effect of ethinyl estradiol and drospirenone combination. Contraception. 2013; 87(3): 358-362, doi: 10.1016/j.contraception.2012.07.005, indexed in Pubmed: 22898361.

13. Ezeh $U$, Pall $M$, Mathur $R$, et al. Association of fat to lean mass ratio with metabolic dysfunction in women with polycystic ovary syndrome. Hum Reprod. 2014; 29(7): 1508-1517, doi: 10.1093/humrep/deu096, indexed in Pubmed: 24813197.

14. Roe AH, Prochaska $E$, Smith $M$, et al. Using the androgen excess-PCOS society criteria to diagnose polycystic ovary syndrome and the risk of metabolic syndrome in adolescents. J Pediatr. 2013; 162(5): 937-941, doi: 10.1016/j.jpeds.2012.11.019, indexed in Pubmed: 23260096.

15. Jafari-Sfidvajani $S$, Ahangari $R$, Hozoori $M$, et al. The effect of vitamin D supplementation in combination with low-calorie diet on anthropometric indices and androgen hormones in women with polycystic ovary syndrome: a double-blind, randomized, placebo-controlled trial. J Endocrinol Invest. 2018;41(5): 597-607, doi: 10.1007/s40618-017-07859, indexed in Pubmed: 29110281.

16. Hausman DB, DiGirolamo M, Bartness TJ, et al. The biology of white adipocyte proliferation. Obes Rev. 2001; 2(4): 239-254, indexed in Pubmed: 12119995.

17. Leal Vd, Mafra D. Adipokines in obesity. Clin Chim Acta. 2013;419:87-94, doi: 10.1016/j.cca.2013.02.003, indexed in Pubmed: 23422739.

18. Jürimäe J. Adipocytokine and ghrelin responses to acute exercise and sport training in children during growth and maturation. Pediatr Exerc Sci. 2014; 26(4): 392-403, doi: 10.1123/pes.2014-0162, indexed in Pubmed: 25372374.

19. Kedikova SE, Sirakov MM, Boyadzhieva MV. Leptin levels and adipose tissue percentage in adolescents with polycystic ovary syndrome. Gynecol Endocrinol. 2013; 29(4): 384-387, doi: 10.3109/09513590.2012.752455, indexed in Pubmed: 23350621.

20. Sadeeqa S, Mustafa T, Latif S. Polycystic Ovarian Syndrome-Related Depression in Adolescent Girls: A Review. J Pharm Bioallied Sci. 2018; 10(2): 55-59, doi: 10.4103/JPBS.JPBS 1 18, indexed in Pubmed: 29962792. 